\title{
Low velocity impact and internal pressure behaviors of unaged E-glass and S- glass/epoxy composite elbow pipe joints
}

\begin{abstract}
This experimental analysis studies the consequences of impact loading on the impact performance and monotonic burst pressure on the level of leakage after impact of E- and Sglass/epoxy composite pipe joints. First, impact tests with three dissimilar energy points (10, 12.5 , and $15 \mathrm{~J}$ ) were applied on composite elbow pipe joints at room temperature, followed by burst pressure tests. Scanning electron microscopy pictures were taken, and the relationship between levels of impact energy on the pipe joints with burst strength was recognized. The results of proposed S-glass/epoxy composite elbow pipe joints were more prominent when were matched with that of a reference specimen, an E-glass/epoxy composite elbow pipe joint. This research proposes a new perspective that impact strength depends upon the increase in time of impact and type of material used.
\end{abstract}

Keyword: E-Glass; S-Glass; Epoxy composite elbow pipe joints 